\title{
REVISTAMATĒRIA
}

\section{Obtenção de austenita expandida (fase S): Nitretação por plasma em baixa temperatura $x$ SHTPN - Parte 1}

\author{
Obtaining S-phase layer: \\ Glow-discharge nitriding at low temperature $x$ \\ SHTPN - Part 1
}

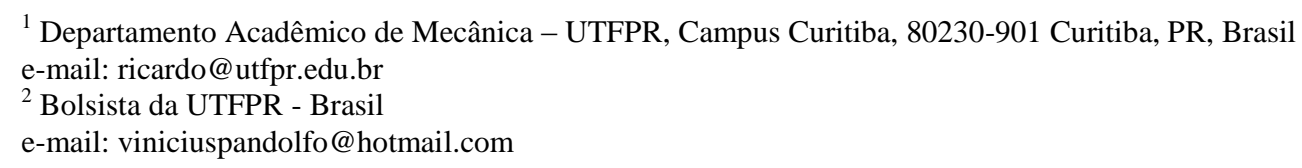

\section{RESUMO}

Corpos de prova de aço inoxidável ISO 5832-1 foram tratados por dois diferentes processos, nitretação por plasma em baixa temperatura e SHTPN, com objetivo de obter camada superficial rica em nitrogênio (fase $S$ ou $\gamma_{\mathrm{N}}$ ) e livre de precipitados. O tempo de nitretação para ambos os processos foi o mesmo $(3 \mathrm{~h})$, de modo a possibilitar um comparativo dos resultados obtidos. Utilizaram-se as seguintes técnicas de análise: microscopia eletrônica de varredura (MEV), microscopia ótica (MO), microdureza, difração de raios-X (DRX) e espectroscopia por dispersão de comprimento de onda. Os resultados indicaram que a nitretação em baixa temperatura possibilita a formação de camada de fase $\mathrm{S}$ com concentrações da ordem de $0,90 \% \mathrm{~N}$ (peso) com espessuras de pouco mais de $2 \mu \mathrm{m}$, enquanto o SHTPN gera camadas com $0,45 \% \mathrm{~N}$ (peso) e espessuras de até $200 \mu \mathrm{m}$.

Palavras-chave: Nitretação por plasma, SHTPN, fase S, aços inoxidáveis, ISO 5832-1.

\begin{abstract}
Samples of stainless steel ISO 5832-1 were nitrided by two different processes, plasma nitriding at low temperature and SHTPN, in order to obtain a nitrogen rich surface layer (S-phase or $\gamma_{\mathrm{N}}$ ) free from precipitates. The nitriding time for both processes was the same $(3 \mathrm{~h})$, to enable a comparison of the results obtained. Treated samples were characterized by means of scanning electron microscopy (SEM), optical microscopy, microhardness, X-ray diffraction (XRD) and wavelength dispersive spectrometry (WDS). The results indicate that low-temperature nitriding enables the formation of S-phase layer with nitrogen concentrations about 0.90 wt. \% with a thickness of $2.15 \mu \mathrm{m}$, while SHTPN generates layers with 0.45 wt.\% and thicknesses up to $200 \mu \mathrm{m}$.
\end{abstract}

Keywords: Plasma nitriding, SHTPN, S-phase, stainless steel, ISO 5832-1.

\section{INTRODUÇÃO}

Os aços inoxidáveis austeníticos são vastamente empregados na indústria por possuírem excelente resistência à corrosão; entretanto, dependendo do meio ao qual estão expostos, podem sofrer corrosão por pite e / ou frestas. Este fato, aliado a baixa dureza e propriedades tribológicas, limita sua aplicabilidade. Várias técnicas vêm sendo empregadas com o objetivo de melhorar as características superficiais destes aços, dentre essas, a

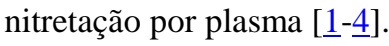

O emprego da nitretação em temperaturas relativamente altas $\left(450{ }^{\circ} \mathrm{C}\right.$ ou mais $)$ promove o aumento da dureza superficial e consequentemente melhora a resistência ao desgaste desses aços. No entanto, ocorre um favorecimento à formação da fase $\mathrm{CrN}$. Tal precipitação promove o empobrecimento de cromo da matriz, reduzindo a resistência à corrosão, como consequência de dificultar a formação da camada passiva característica desses materiais $[\underline{5}, \underline{6}]$. 
Para os aços inoxidáveis a grande maioria dos efeitos benéficos do nitrogênio está associada à sua presença em solução sólida [7]. Desta forma a utilização da nitretação por plasma fica restrita ao uso desse processo a baixa temperatura, no qual ocorre somente a formação da fase $\mathrm{S}$, também conhecida como austenita expandida $\left(\gamma_{\mathrm{N}}\right)[\underline{1}, \underline{8}, \underline{9}]$. Nos anos 80 , Zhang e Bell [10] foram os primeiros pesquisadores a estudar a nitretação por plasma em baixas temperaturas, que também foi estudada independentemente por Ichii et al. [11]. Na nitretação em baixas temperaturas, o aumento na dureza e a consequente melhoria na resistência ao desgaste deve-se à supersaturação de nitrogênio na camada nitretada. Essa supersaturação produz uma elevada densidade de discordâncias e tensões compressivas, que podem, adicionalmente, aumentar a resistência à fadiga de peças submetidas a esses tratamentos. Observa-se ainda que, quanto maior a saturação de nitrogênio, maior a dureza [12]. No entanto, nessas temperaturas, produzem-se camadas superficiais de austenita expandida $\left(\gamma_{\mathrm{N}}\right)$ ou fase $\mathrm{S}$ muito finas $[\underline{13}, \underline{14}]$.

Outros processos têm sido empregados visando à adição de nitrogênio em solução sólida em aços inoxidáveis. Os mais comuns são a implantação iônica [15] e a nitretação gasosa a alta temperatura (HTGN) [16]. Mais recentemente o processo denominado "Solution Heat Treatment after Plasma Nitriding" (SHTPN) foi proposto como um novo método para enriquecimento superficial de nitrogênio no estado sólido, tendo apresentado bons resultados na melhoria da resistência à corrosão de aços inoxidáveis [17, 18]. Este método consiste em dois passos: primeiro, nitretação por plasma a alta temperatura (PN) (acima de $873 \mathrm{~K}$ ) objetivando a obtenção de camadas nitretadas espessas e ricas em nitrogênio (independente da formação de nitretos), seguido pelo segundo passo, onde o material passa por um tratamento térmico de solubilização (SHT), visando à difusão do nitrogênio e a consequente formação de uma camada espessa, rica em nitrogênio, e livre de precipitados.

Em trabalho anterior [17] verificou-se, para o aço ISO 5832-1, uma correlação linear entre os valores de microdureza da fase $\mathrm{S}$ e a concentração de nitrogênio em solução sólida. Esta pode ser descrita pela equação (1) e permite estimar o teor de nitrogênio em solução sólida a partir de valores de microdureza.

$$
\% \mathrm{~N}=0,0105 \mathrm{HV}-2,4116
$$

A resistência à corrosão pode ser mantida ou até mesmo aumentada por esses tratamentos, principalmente a corrosão por pite, a qual pode ser avaliada qualitativamente pelo PREN ("Pitting Resistance Equivalent Number"). Este parâmetro é relacionado à corrosão por pite em meios contendo cloretos e pode ser calculado a partir da seguinte equação:

$$
\mathrm{PREN}=\% \mathrm{Cr}+3,3(\% \mathrm{Mo})+16(\% \mathrm{~N})
$$

A presente pesquisa objetiva comparar os resultados obtidos pelo processamento por plasma em baixa temperatura e os do SHTPN na obtenção de camadas monofásicas de austenita expandida $\left(\gamma_{N}\right)$ ou fase $S$, no aço inoxidável austenítico ISO 5832-1. Em uma segunda parte deste artigo será realizado um estudo comparativo de desempenho envolvendo corrosão e desgaste.

\section{MATERIAIS E MÉTODOS}

Corpos de prova cilíndricos com 15,0 mm de altura foram obtidos a partir de uma barra de diâmetro 15,8 mm. Depois de cortados, os corpos de prova foram lixados em lixas de até 1000 mesh e polidos em suspensão de alumina $1 \mu \mathrm{m}$. O material empregado na pesquisa foi o aço inoxidável ISO 5832-1, cuja composição química é apresentada na Tabela 1. A microestrutura de partida foi $100 \%$ austenítica, com diâmetro médio de grão de $7,72 \pm 0,25 \mu \mathrm{m}$ e dureza inicial de $208 \pm 3 \mathrm{HV}$.

Tabela 1: Composição química do aço inoxidável austenítico ISO 5832-1 (\% peso).

\begin{tabular}{l|l|l|l|l|l|l|l}
\hline $\mathbf{C}$ & $\mathbf{M n}$ & $\mathbf{S i}$ & $\mathbf{C r}$ & $\mathbf{N i}$ & Mo & $\mathbf{N}$ & Fe \\
\hline 0,017 & 1,750 & 0,350 & 17,800 & 14,300 & 2,760 & 0,077 & Balanço \\
\hline
\end{tabular}

Antes do início do processamento as amostras foram submetidas à limpeza por ultrassom em álcool etílico durante um período de 1 hora, visando eliminar contaminantes provenientes da etapa de preparação.

A nitretação foi realizada em um reator provido de fonte pulsada pertencente ao Laboratório de Plasma da UTFPR. Os parâmetros de nitretação variaram conforme objetivo: nitretação a baixa temperatura e nitretação objetivando posterior solubilização (SHTPN). 
Os parâmetros empregados no processo SHTPN foram baseados em trabalho anterior [17] e estão resumidos na Tabela 2 .

Tabela 2: Resumo dos parâmetros empregados para o processo SHTPN [17].

\begin{tabular}{l|l|l}
\hline PARÂMETRO & NITRETAÇÃO POR PLASMA (PN) & TRAT. DE SOLUBILIZAÇÃO (SHT) \\
\hline Temperatura & $750^{\circ} \mathrm{C}$ & $1200{ }^{\circ} \mathrm{C}$ \\
\hline Tempo & $3 \mathrm{~h}$ & $45 \mathrm{~min}$ \\
\hline Meio & Atmosfera: $90 \% \mathrm{~N}_{2} / 10 \% \mathrm{H}_{2}$ & Banho de sais fundidos \\
\hline
\end{tabular}

Para o estudo da nitretação em baixa temperatura foram escolhidas três temperaturas para tratamento, objetivando a obtenção de uma camada constituída apenas da fase $\mathrm{S}$ e de maior espessura possível, considerando o mesmo tempo de nitretação empregado no SHTPN. As escolhidas foram: $350{ }^{\circ} \mathrm{C}, 400{ }^{\circ} \mathrm{C}$ e $450{ }^{\circ} \mathrm{C}$, sendo processadas seis amostras para cada uma delas. Os demais parâmetros de tratamento são apresentados na Tabela 3.

Tabela 3: Parâmetros empregados na nitretação em baixa temperatura.

\begin{tabular}{l|l}
\hline PRESSÃO & $533 \mathrm{~Pa}$ (4 Torr) \\
\hline TEMPO & $3 \mathrm{~h}$ \\
\hline ATMOSFERA & $20 \% \mathrm{~N}_{2} / 80 \% \mathrm{H}_{2}$ \\
\hline
\end{tabular}

Após a nitretação as amostras foram resfriadas até $300^{\circ} \mathrm{C}$ por convecção forçada na mistura, e então resfriadas sob vácuo até a temperatura ambiente.

As amostras nitretadas, bem como as que passaram pelo processo SHTPN, foram cortadas longitudinalmente e embutidas a quente em resina (baquelite). Foram então preparadas utilizando processo metalográfico adequado, de modo a avaliar a morfologia, espessura e o perfil de microdureza das camadas obtidas. A avaliação da morfologia da camada nitretada foi realizada empregando microscopia ótica (MO) e microscopia eletrônica de varredura (MEV). Em ambos os casos, ataque eletrolítico com solução aquosa de ácido oxálico (10\%) foi empregado. Medidas da espessura da camada nitretada foram obtidas com uso do analisador de imagens (Image Pro-Plus ${ }^{\circledR}$ ) acoplado a um microscópio ótico. O perfil de microdureza (indentador Vickers, 50 gf) foi obtido com uso de um microdurômetro Schimadzu modelo HMV 2. Para as medidas de topo empregou-se carga de 100 gf. Análises por difração de raios-X (DRX) foram realizadas para identificação das fases presentes em um difratômetro Philips - X'Pert utilizando-se radiação Cuk $\alpha(\lambda=1,54060)$, corrente de $30 \mathrm{~mA}$ e voltagem de $40 \mathrm{kV}$. A faixa angular de $20^{\circ}$ a $120^{\circ}(2 \theta)$ foi investigada a uma velocidade de varredura do goniômetro de $0,05^{\circ} / \mathrm{s}$.

Para as amostras solubilizadas realizou-se também a quantificação do nitrogênio utilizando-se espectroscopia por dispersão de comprimento de onda (WDS). As medidas de nitrogênio foram realizadas no corte longitudinal das amostras, da superfície para o interior das mesmas. Realizaram-se também medidas magnéticas utilizando um ferritoscópio de marca Elcometer, modelo 159, sendo que estas medidas foram feitas após lixamento, de forma a eliminar óxidos presentes, os quais poderiam influir nos resultados. O limite de detecção do aparelho é $0.1 \%$ de ferrita.

\section{RESULTADOS E DISCUSSÃO}

\subsection{SHTPN}

Nitretação por plasma (PN) - A Figura 1 apresenta a micrografia da camada nitretada conforme parâmetros da Tabela 2.

Verifica-se que a camada nitretada é composta pelas porções correspondentes à camada de compostos (Região A) e camada de difusão (Região B). Observam-se ainda diferenças morfológicas ao longo da camada nitretada. Estas diferenças são similares as já discutidas em trabalhos anteriores [17, 19-21] .

As fases presentes na superfície da amostra foram identificadas por DRX como sendo: nitreto de cromo $(\mathrm{CrN})$, austenita $(\gamma)$ e martensita $\left(\alpha^{\prime}\right)$, conforme difratograma da Figura 2. 
A presença de austenita $(\gamma)$ está relacionada com a composição inicial do material, já a formação do nitreto de cromo $(\mathrm{CrN})$ era esperada em função da temperatura empregada no processamento. Com respeito à martensita $\left(\alpha^{\prime}\right)$, sua presença já foi relatada e discutida em trabalho anterior [17].

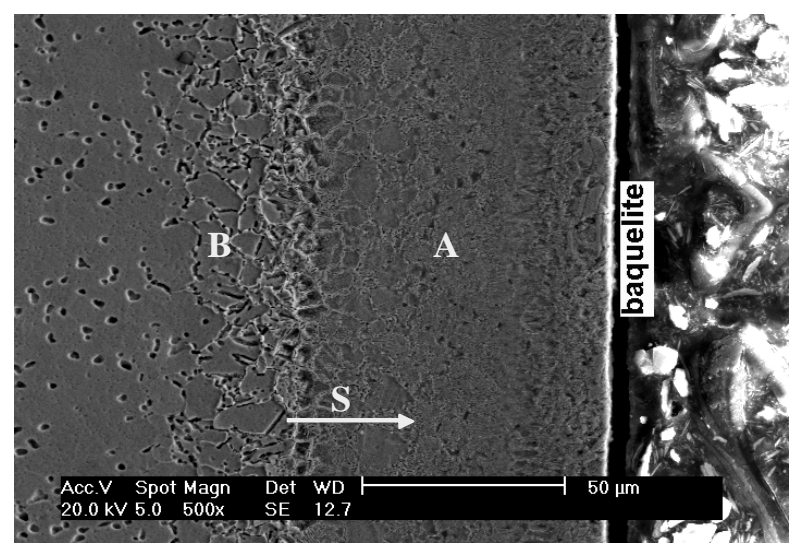

Figura 1: Micrografia do aço ISO 5832-1 nitretado em $750{ }^{\circ} \mathrm{C}$ por $3 \mathrm{~h}$. Ataque eletrolítico: ácido oxálico $10 \%$. S indica a direção da superfície [17].

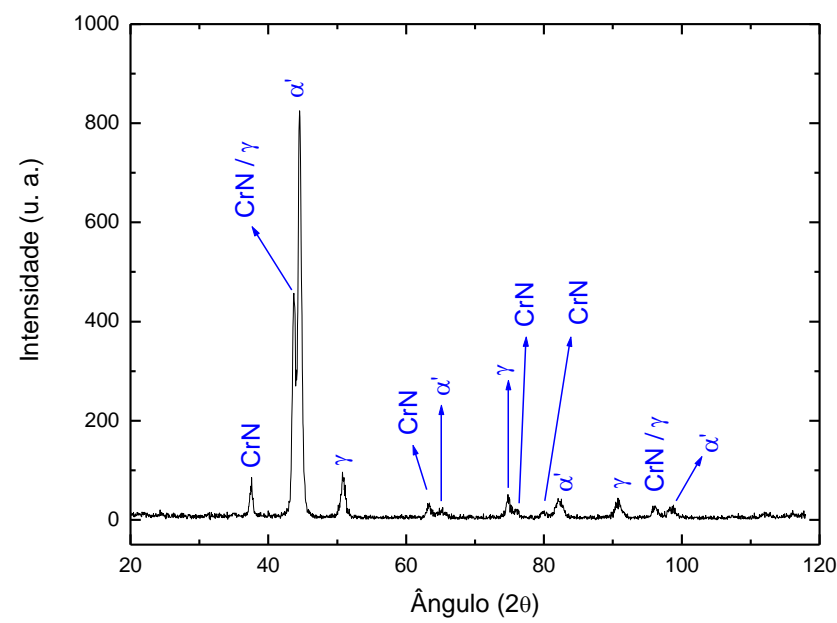

Figura 2: Difratograma do aço ISO 5832-1 nitretado em $750{ }^{\circ} \mathrm{C}$ por $3 \mathrm{~h}$.

Comparando-se os resultados obtidos com processamentos realizados em menores temperaturas, fica evidente a grande diferença no tocante às espessuras das camadas. Enquanto Gontijo et al. [12] obtiveram, no aço AISI 304L, camadas formadas unicamente pela porção correspondente a de compostos com espessuras de $12,1 \mu \mathrm{m}$ em $450{ }^{\circ} \mathrm{C}$, para o mesmo tempo de processamento, empregando $750{ }^{\circ} \mathrm{C}$, alcançou-se camadas de $102 \pm 3 \mu \mathrm{m}$. Neste caso, $78 \mu \mathrm{m}$ de camada de compostos e $24 \mu \mathrm{m}$ de camada de difusão, conforme medições realizadas em imagens semelhantes a da Figura 1.

Tratamento de solubilização (SHT) - Objetivando obtenção de camada monofásica de fase S (austenita expandida $-\gamma_{\mathrm{N}}$ ), procedeu-se a solubilização empregando-se parâmetros descritos na Tabela 2.

A micrografia do aço após o referido tratamento permitiu concluir que a mesma é condizente com uma estrutura $100 \%$ austenítica, livre de precipitados.

De modo a sanar dúvidas de eventuais precipitados que pudessem existir após a solubilização, realizou-se ataque intenso sobre a micrografia obtida, a qual pode ser vista na Figura 3.

Mesmo após ataque intenso sobre a amostra, não se observa nenhuma característica condizente com a existência de precipitados, como por exemplo, ataque intergranular. As alterações observadas na coloração dos grãos se devem à diferença de orientação cristalográfica. A análise de fases também foi realizada por 
DRX, cujo difratograma é apresentado na Figura 4.

O resultado obtido no difratograma corrobora com os resultados anteriores, mostrando o sucesso do tratamento de solubilização e a obtenção de uma estrutura livre de precipitados, $100 \%$ austenítica. Não fica evidenciada a formação da fase $\mathrm{S}$, que deveria indicar picos mais largos e ligeiramente deslocados para a esquerda. A formação desta fase foi então confirmada pelo endurecimento proveniente da formação de solução sólida de nitrogênio na fase $\gamma$. Após a dissolução da camada nitretada e a difusão do nitrogênio para o interior das amostras, as mesmas encontram-se com teores superficiais de nitrogênio, em solução sólida, maiores do que na condição inicial e consequentemente com maiores valores de dureza superficial.

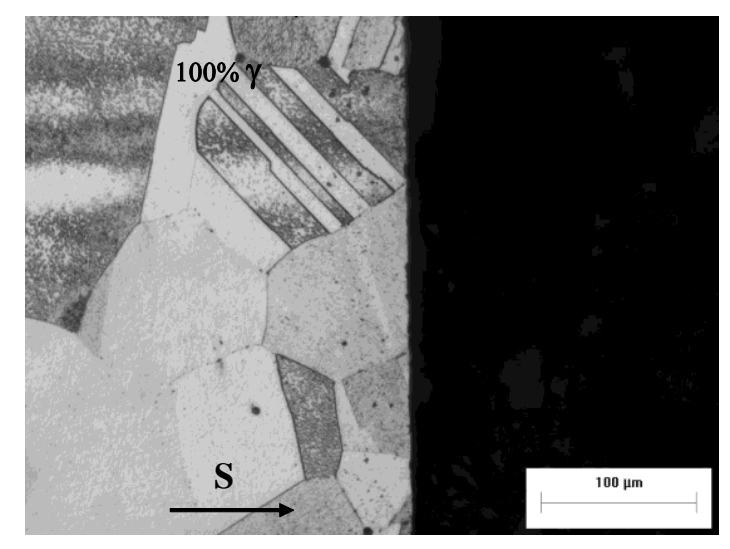

Figura 3: Micrografia do aço ISO 5832-1 nitretado em $750{ }^{\circ} \mathrm{C}$ por $3 \mathrm{~h}$ e solubilizado em $1200{ }^{\circ} \mathrm{C}$ por 45 min (ataque intenso). Ataque eletrolítico: ácido oxálico $10 \%$. S indica a direção da superfície.

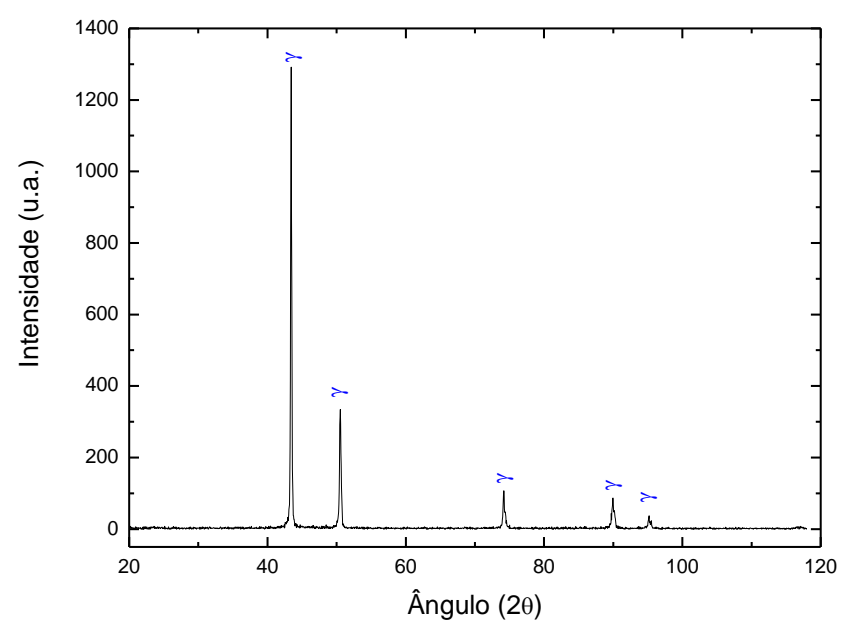

Figura 4: Difratograma do aço ISO 5832-1 nitretado em $750{ }^{\circ} \mathrm{C}$ por $3 \mathrm{~h}$ e solubilizado em $1200{ }^{\circ} \mathrm{C}$ por $45 \mathrm{~min}$.

A dissolução da camada nitretada se deve à instabilidade dos nitretos na temperatura de solubilização e a consequente difusão do nitrogênio devido à diferença de concentração existente entre a superfície e o interior das amostras.

A Figura 5 apresenta o perfil de dureza para a amostra após o tratamento SHTPN, comparando ainda com a dureza após a nitretação (PN) e a dureza inicial das amostras.

O perfil de microdureza indica, para a amostra após SHTPN, uma camada modificada total de $400 \mu \mathrm{m}$, com distribuição uniforme de dureza (ou levemente linear, indicando baixo gradiente de concentração de nitrogênio) até uma profundidade de $200 \mu \mathrm{m}$, ou seja, corrobora com a formação da fase $\mathrm{S}$, conforme discutido anteriormente. Além disto, para a região de dureza uniforme $(272 \pm 8 \mathrm{HV})$, realizou-se a quantificação de nitrogênio utilizando-se WDS, que indicou um valor médio de $0,45 \%$ em peso. Análise realizada com ferritoscópio não indicou presença de ferrita.

A Tabela 4 resume os principais resultados obtidos com aplicação do processo SHTPN na obtenção de 
camada monofásica de fase $S$ (austenita expandida $-\gamma_{\mathrm{N}}$ ).

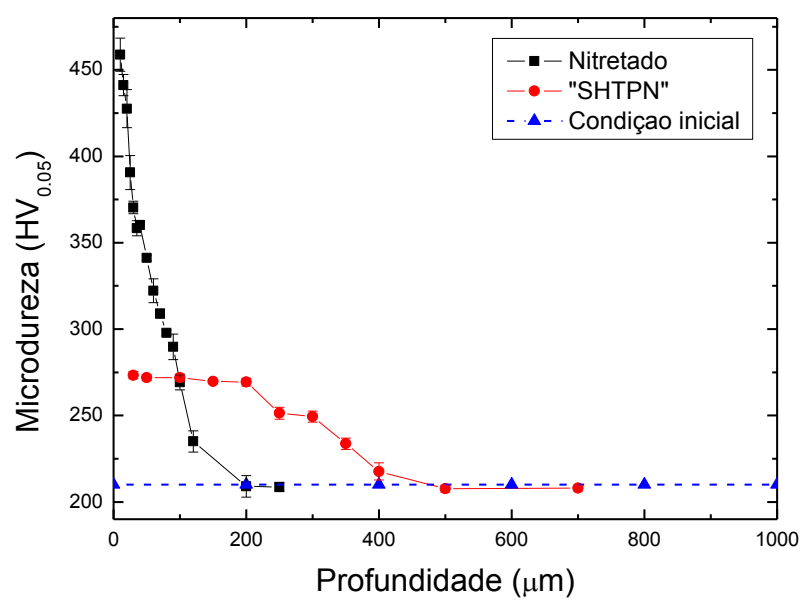

Figura 5: Comparativo de dureza: Nitretado, SHTPN, condição inicial [17].

Tabela 4: Resumo dos principais resultados obtidos pelo SHTPN - adaptado de [17].

\begin{tabular}{l|l|l|l|l|l}
\hline \multicolumn{2}{l|}{ PROCESSAMENTO } & \multicolumn{2}{l|}{ ESPESSURA DE CAMADA } & \% N (PESO) REGIÃO & \multirow{2}{*}{$\begin{array}{l}\text { \% FERRITA } \\
\text { UNIFORME }\end{array}$} \\
\hline Nitretação & Solubilização & Total & CDU* & & \\
\hline $750^{\circ} \mathrm{C} / 3 \mathrm{~h}$ & $1200{ }^{\circ} \mathrm{C} / 45 \mathrm{~min}$ & $400 \mu \mathrm{m}$ & $200 \mu \mathrm{m}$ & 0,45 & 0 \\
\hline
\end{tabular}

*Camada com Dureza Uniforme.

De posse da composição química do aço indicada na Tabela 2, do valor de nitrogênio indicado na Tabela 4 e da equação (2), verifica-se que o processo SHTPN produz um aumento do PREN (de 28,14 para 34,11), sendo um indicativo de melhoria na resistência a corrosão por pite.

\subsection{Nitretação a baixa temperatura}

Para todas as temperaturas de processamento percebe-se a formação de uma fina camada sobre a superfície das amostras tratadas. Análise por DRX não indicou a formação de compostos para nenhuma das temperaturas, tendo como resultado difratograma similar ao da Figura 4 com picos ligeiramente mais largos e deslocados para a esquerda, ou seja, condizente com austenita expandida $\left(\gamma_{\mathrm{N}}\right)$ ou fase $\mathrm{S}$.

A micrografia da amostra nitretada a $450{ }^{\circ} \mathrm{C}$ (Figura 6 (c)), indica, na região da camada superficial, ataque em contorno de grão. Embora compostos não tenham sido identificados, este aspecto é condizente com a precipitação de $\mathrm{CrN}$. Acredita-se que a quantidade formada de $\mathrm{CrN}$ esteja abaixo do limite de detecção da análise por DRX.

As espessuras das camadas da fase $\mathrm{S}$, apresentadas na Tabela 5, aumentam com a temperatura de tratamento, tendo valores inferiores aos apresentados por Gontijo et. al. [12] para as mesmas condições de tratamento, obtidos para os aços AISI 304L e AISI 316L. As diferenças nas espessuras podem ser justificadas por um menor coeficiente de difusão e uma maior solubilidade do nitrogênio decorrente do maior teor de molibdênio no aço ISO 5832-1.

Em virtude das pequenas espessuras de camadas de fase $S$ formadas, não foi possível a medição de microdureza na secção longitudinal correspondente a esta região. Optou-se então pela medição de topo (Tabela 6), mesmo sabendo que a espessura de camada não seria suficiente de modo a atender os requisitos da norma ABNT [22].

Como a espessura da camada influencia a dureza e os valores medidos nas amostras tratadas são a interação da dureza da camada e de parte do substrato, têm-se valores maiores à medida que a parcela do substrato, que contribui com a medida, diminui com o aumento da camada modificada. No entanto, para o caso específico, acredita-se que a parcela referente a este efeito seja menor quando comparado ao aumento da dureza associado à variação da concentração de nitrogênio na fase $\mathrm{S}$, ou ainda, a presença de $\mathrm{CrN}$, no caso da amostra nitretada a $450{ }^{\circ} \mathrm{C}$. 
A Figura 6 apresenta as micrografias das amostras nitretadas em 350,400 e $450{ }^{\circ} \mathrm{C}$.

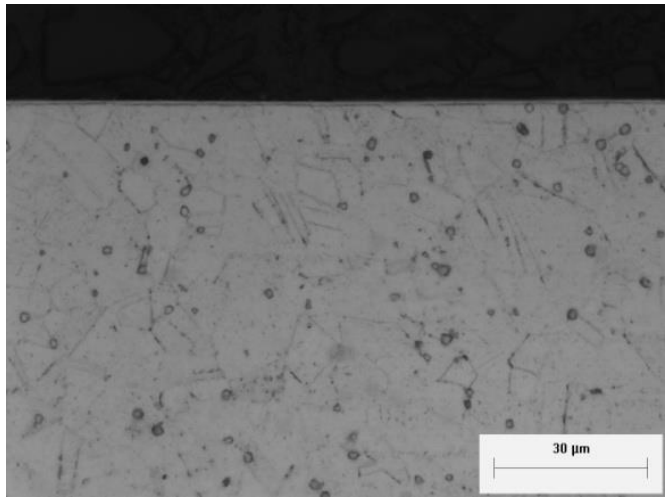

(a)

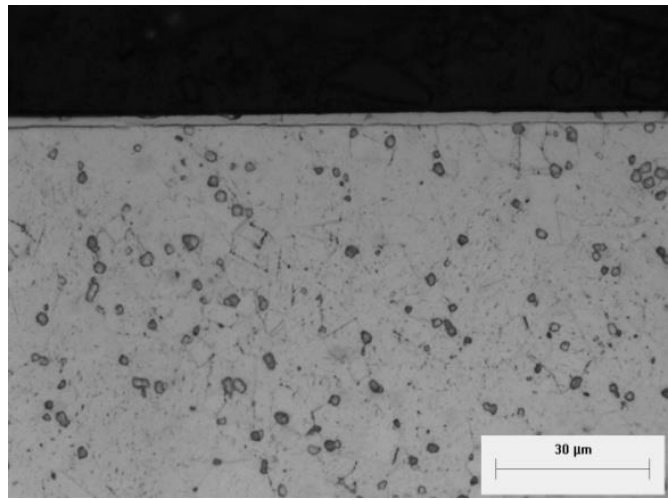

(b)

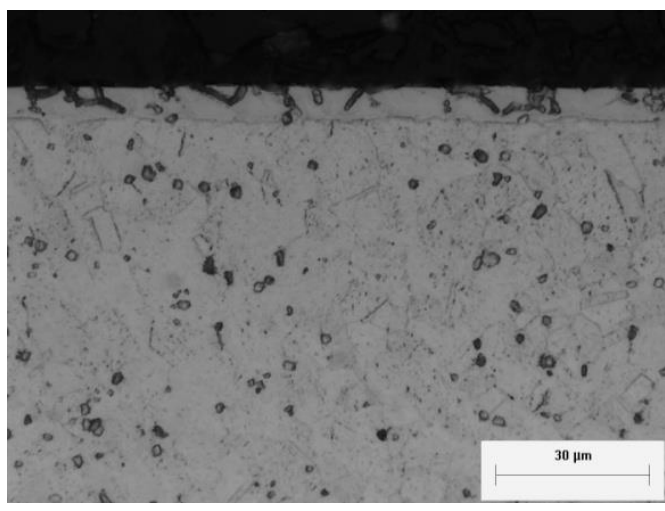

(c)

Figura 6: Micrografia do aço ISO 5832-1 nitretado por $3 \mathrm{~h} \mathrm{em:} \mathrm{(a)} 350{ }^{\circ} \mathrm{C}$, (b) $400{ }^{\circ} \mathrm{C}$, (c) $450{ }^{\circ} \mathrm{C}$. Ataque eletrolítico: ácido oxálico $10 \%$.

Tabela 5: Espessuras das camadas formadas no aço ISO 5832-1 nitretado por $3 \mathrm{~h}$ a diferentes temperaturas.

\begin{tabular}{l|l}
\hline TEMPERATURA $\left[{ }^{\circ} \mathrm{C}\right]$ & ESPESSURA $[\boldsymbol{\mu m}]$ \\
\hline 350 & $1,21 \pm 0,36$ \\
\hline 400 & $2,15 \pm 0,55$ \\
\hline 450 & $5,98 \pm 0,97$ \\
\hline
\end{tabular}

Tabela 6: Microdureza do topo das amostras do aço ISO 5832-1 nitretado por $3 \mathrm{~h}$ a diferentes temperaturas.

\begin{tabular}{l|l}
\hline $\begin{array}{l}\text { TEMPERATURA DE } \\
\text { NITRETAÇÃO [ํㅜ }\end{array}$ & MICRODUREZA [HV $\left.\mathbf{0}_{\mathbf{0}}\right]$ \\
\hline 350 & $360 \pm 12$ \\
\hline 400 & $544 \pm 14$ \\
\hline 450 & $773 \pm 12$ \\
\hline
\end{tabular}

Para as amostras processadas em 350 e $400{ }^{\circ} \mathrm{C}$, considerando o endurecimento como consequência da formação de solução sólida e baseado na equação (1), pode-se estimar a concentração de nitrogênio nestas camadas. Estes valores, bem como os principais resultados obtidos com aplicação da nitretação em baixa temperatura na obtenção de camada monofásica de fase $S$ (austenita expandida $-\gamma_{N}$ ) são apresentados na Tabela 7 . 
Tabela 7: Resumo dos principais resultados obtidos na nitretação em baixa temperatura.

\begin{tabular}{l|l|l|l}
\hline NITRETAÇÃO & $\begin{array}{l}\text { ESPESSURA DE } \\
\text { CAMADA }\end{array}$ & $\begin{array}{l}\text { \% N (PESO) } \\
\text { ESTIMADO }\end{array}$ & \% FERRITA \\
\hline $350^{\circ} \mathrm{C} / 3 \mathrm{~h}$ & $1,21 \pm 0,36$ & 0,59 & 0 \\
\hline $400^{\circ} \mathrm{C} / 3 \mathrm{~h}$ & $2,15 \pm 0,55$ & 0,90 & 0 \\
\hline
\end{tabular}

De posse da composição química do aço indicada na Tabela 2, dos valores de nitrogênio indicados na Tabela 7 e da equação (2), verifica-se, assim como no processo SHTPN, que a nitretação por plasma em baixa temperatura produz aumento do PREN. Este aumento é de 28,14 para 36,35 para a nitretação realizada em $350{ }^{\circ} \mathrm{C}$ e de 28,14 para 41,31 para a de $400{ }^{\circ} \mathrm{C}$. Mais uma vez tem-se um indicativo de melhoria na resistência à corrosão por pite.

\section{CONCLUSÕES}

Tanto o processo SHTPN, quanto à nitretação por plasma a baixa temperatura, formou camadas superficiais de fase $\mathrm{S}$, porém, com diferenças acentuadas, principalmente no tocante as espessuras das referidas camadas. No primeiro processo alcançou-se espessura de camada de $200 \mu \mathrm{m}$, enquanto o segundo de pouco mais de $2 \mu \mathrm{m}$ para o tratamento realizado em $400{ }^{\circ} \mathrm{C}$.

A concentração de nitrogênio na camada modificada é outra diferença observada. No processo SHTPN o valor medido foi de $0,45 \%$ em peso de nitrogênio, enquanto o estimado para a nitretação foi de $0,90 \%$ em peso para o processamento realizado em $400{ }^{\circ} \mathrm{C}$.

As diferenças observadas tendem a influenciar o desempenho para o material tratado (SHTPN x Nitretação). Acredita-se que a resistência à corrosão do material tratado, por um ou outro processo, não tenha diferenças significativas, visto que ambos possuem um valor de PREN bastante alto. Estudos preliminares indicam uma transpassivação coincidindo com o potencial de hidrólise da água.

A principal diferença deve estar associada a aplicações envolvendo desgaste, onde a vida útil do material tratado por SHTPN (devido a maior espessura de camada) deve superar em muito o tratado por plasma a baixa temperatura. Estudos envolvendo tais condições serão realizados e seus resultados publicados em artigo futuro.

\section{AGRADECIMENTOS}

Os autores gostariam de agradecer a Villares Metals pela doação do material empregado na pesquisa.

\section{BIBLIOGRAFIA}

[1] LARISCH, B., BRUSKY, U., SPIES, H. J., "Plasma nitriding of stainless steels at low temperatures", Surface and Coatings Technology, v.116-119, pp. 205-211, 1999.

[2] MENTHE, E., RIE, K. T., "Further investigation of the structure and properties of austenitic stainless steel after plasma nitriding”, Surface and Coatings Technology, v.116-119, pp. 199-204, 1999.

[3] SOUZA, S. D., OLZON-DIONYSIO, M., MIOLA, E. J., et al., "Plasma nitriding of sintered AISI 316L at several temperatures", Surface and Coatings Technology, v.184, pp. 176-181, 2004.

[4] MENTHE, E., BULAK, A., OLFE, J., et al., "Improvement of the mechanical properties of austenitic stainless steel after plasma nitriding”, Surface and Coatings Technology, v.133-1134, pp. 259-263, 2000.

[5] LIANG, W., JUNCAI, S., XIAOLEI, X., "Low pressure plasma arc source ion nitriding compared with glow-discharge plasma nitriding of stainless steel”, Surface and Coatings Technology, v.145, pp. 31-37, 2001.

[6] LIANG, W., "Surface modification of AISI 304 austenitic stainless steel by plasma nitriding", Applied Surface Science, v. 211, pp. 308-314, 2003. 
[7] GAVRILJUK, V. G., BERNS, H. High nitrogen steels, Berlin, Springer - Verlag, 1999.

[8] XI, Y. T., LIU, D. X., HAN, D., "Improvement of mechanical properties of martensitic stainless steel by plasma nitriding at low temperature”, Acta Metallurgica Sinica, v. 21, pp. 21-29, 2008.

[9] BERNARDELLI, E. A., BORGES, P. C., FONTANA, L. C., et al., "Role of plasma nitriding temperature and time in the corrosion behaviour and microstructure evolution of 15-5 PH stainless steel", Kovové Materiály, v. 48, pp. 105-116, 2010.

[10] ZHANG, Z. F., BELL, T., "Structure and corrosion resistance of plasma nitrided stainless steel”, Surface Engineering, v. 1, pp. 131-136, 1985.

[11] ICHII, K., FUJIMURA, K., TAKAO, T., "Structure of the ion-nitrided layer of 18-8 stainless steel", Technology Reports of the Kansai University, v. 27, pp. 135-144, 1986.

[12] GONTIJO, L. C., MACHADO, R., CASTELETTI, L. C., et al., "Comparação entre os comportamentos dos aços inoxidáveis AISI 304L e AISI 316L nitretados a plasma”, Revista Brasileira de Aplicações de Vácuo, v. 26, n. 3, pp. 145-150, 2007.

[13] BORGIOLI, F., FOSSATI, A., GALVANETTO, E., et al., "Glow-discharge nitriding of AISI 316L austenitic stainless steel: influence of treatment pressure”, Surface Coatings \& Technology, v. 200, pp. 55055513, 2006.

[14] FOSSATI, A., BORGIOLI, F., GALVANETTO, E., et al., "Glow-discharge nitriding of AISI 316L austenitic stainless steel: influence of treatment time”, Surface Coatings \& Technology, v. 200, pp. 3513-3517, 2006.

[15] ABREU, C. M., CRISTÓBAL, M. J., MERINO, P., et al, "Electrochemical behaviour of an AISI 304L stainless steel implanted with nitrogen”, Electrochimica Acta, v. 53, pp. 6000-6007, 2008.

[16] GARZÓN, C. M., TSCHIPTSCHIN A. P., "Nitretação em alta temperatura de aços inoxidáveis", Revista Matéria, v. 10, n. 4, pp. 502-525, 2005.

[17] REIS, R. F., MALISKA, A. M., BORGES, P. C., "Nitrogen surface enrichment of austenitic stainless steel ISO 5832-1”, J Mater Sci, v. 46, pp. 846-854, 2011.

[18] BORGES, P. C., ROCHA, L. A., "Solution heat treatment of plasma nitrided 15-5PH stainless steel Part I: Improvement of the corrosion resistance”, Kovové Materiály, v. 49, pp. 107-117, 2011.

[19] REIS, R. F., Elevação do teor superficial de nitrogênio no aço inoxidável austenítico ISO 5832-1, Tese de D. Sc., UTFPR, Curitiba, PR, Brasil, 2007.

[20] REIS, R. F., MALISKA, A. M., BORGES, P. C., "Nitretação a plasma do aço ISO 5832-1: Influência de temperaturas elevadas de processamento", Revista Brasileira de Aplicações de Vácuo, v. 26, pp. 205-210, 2007.

[21] REIS, R. F., MALISKA, A. M., BORGES, P. C., "Nitretação a plasma do aço ISO 5832-1: Influência do tempo de tratamento", Revista Matéria, v. 13, n. 2, pp. 304-315, 2008.

[22] ASSOCIAÇÃO BRASILEIRA DE NORMAS TÉCNICAS, Materiais metálicos - Dureza Vickers Parte 1: Medição da dureza Vickers, NBR NM - 188-1, Rio de Janeiro, 1999. 